consent, as they move within the NHS, house officers may be unaware that they are not protected against prescribed diseases such as tuberculosis and hepatitis B. It may well be that Lewisham Hospital's handbook mentions the occupational health department.

Luisa Dillner's review of Stress and the Medical Profession seems to confirm my views. ${ }^{2}$ The penultimate paragraph suggests that doctors need an accessible counselling service and an occupational health service that is geared to recognising stress.

The standard and quality of occupational health services vary considerably within the NHS, but it is essential that all staff, including doctors, become more aware of the services they offer.

B S BAKER

Occupational Health Department,

Brighton Health Authority,

Brighton BN2 1HA

1 Gale R, Jackson G, Nicholls $M$. How to run an induction meeting for house officers. BM7 1992:304:1619-20. (20 June.)

Dillner L. "Avoidable" pressures could relieve doctors' stres. BMF 1992;304:1587. (20 June.)

\section{Unnecessary hospitalisation in a psychiatric rehabilitation unit}

EDITOR, - Peter H Dick and colleagues' paper highlighting delayed discharges from the Dundee psychiatric rehabilitation unit raises several points of interest to doctors in all specialties.' The title and introduction led us to believe that concrete proposals leading to more rapid turnover of beds would be discussed, but, sadly, they are not.

Discharge to unsuitable accommodation is mentioned and may be one method of unblocking beds in the short term. In our experience this practice often leads to rapid readmission. If the original discharging psychiatric unit or other psychiatric departments are unable to readmit these patients then either an acute medical unit or an acute geriatric unit becomes involved.

From the figures given we see that the average turnover of the Dundee rehabilitation unit is just under one patient a week, but we are not given the number of beds in the unit. As the number of beds available is often limited geriatricians may have acute geriatric beds blocked by patients awaiting transfer to their local psychiatric unit. Bed blocking and delayed discharges can therefore affect many specialties either directly or indirectly.

Our department uses a multidisciplinary team to identify potential problems with discharge soon after patients' arrival. This team meets each week to discuss all patients in the department. By highlighting potential problems at an early stage we aim to decrease the time spent in an acute hospital bed.

Bed blocking is a problem in all specialties. We are fortunate in having both government funded and privately funded residential accommodation and nursing home facilities which act as an extension of geriatric long term care beds. We wonder if the previous policy of closing long term psychiatric beds without adequate funding for alternative accommodation in the community may have played a part in the present situation.

We are concerned that this problem may become more pronounced when the change in funding for community long term care from the government (Department of Social Security) to local authorities takes place next April.

KEVIN SHOTLIFF ABHIRAM PRASAD

Department of Geriatric Medicine, DEBESH MUKHERJEE

\section{St George's Hospital,}

London SW 17 ORE

1 Dick PH, Crombie IK, Durham T, McFee C, Primrose M, Mitchell S. Unnecessary hospitalisation in a psychiatric rehabilitation unit. BMF 1992:304:1544. (13 June.)

\section{Ernest Saunders: diagnostic dilemma}

EDITOR,-In passing judgment on the basis of what they have read in the newspapers regarding the medical evidence in Mr Ernest Saunders's appeal Robert Howard and colleagues are guilty of the very accusation they make: of basing definite views on inadequate information.' They also lose sight of the fact that the Appeal Court is not a clinical case conference. If that was so the issue of presenile dementia would not have been raised in front of $\mathrm{Mr}$ Saunders let alone the world in general.

The case against his deterioration in prison being due to a dementia was well presented by $\mathrm{Dr}$ George Perkin, who considered that any decision should be delayed. It was made clear by everyone who gave evidence that the diagnosis was not certain, and in a different situation one would obviously have waited for less equivocal diagnostic evidence. Their lordships no doubt took the view that it was better to be safe than sorry and reduced $\mathrm{Mr}$ Saunders's prison term to reflect their concern. Considering that $\mathrm{Mr}$ Saunders had already served a prison sentence for a first offence of theft, they thereby eschewed the possibility of him spending further time in penal conditions if in fact his days were so grimly numbered.

Some people seem angry about the case, feeling cheated of their pound of flesh and that $\mathrm{Mr}$ Saunders has a duty to deteriorate to provide it. I am sure that Howard and colleagues have no such base motives but are entirely concerned with the credibility of their specialty. Specialties of all sorts, however, need to be put in the human context that prevails in relation to individual cases, and the Appeal Court had the advantage, which Howard and colleagues have not, of weighing the clinical evidence within the wider context of the judicial situation. I am sure that Howard and colleagues will want to join me in expressing pleasure that $\mathrm{Mr}$ Saunders is apparently so much better.

Langdon Hospital,

P L G GALLWEY

Dawlish, Devon EX7 0NR

Howard R, Levestone S, Levy R. Ernest Saunders: diagnostic dilemma. BMf 1992;304:1568. (13 June.)

\section{Patient's charter in outpatient services}

EDIToR,-In his editorial Charles Collins states that specialty outpatient clinics will have to develop a rigid booking pattern to be able to give specific appointment times but does not mention how specialties outside surgery will achieve this with present resources or the loss of the flexibility that allows patients with serious conditions to be seen quickly without admission to a scarce inpatient bed.

In oncology, with an open booking system and a varying number of new patients each week, there will inevitably be differences in waiting time, often over the 30 minute target. But the advantages to patients of reducing their waiting time at home and the accompanying anxiety, the early discussion of their diagnosis and treatment plan, and reducing the time to the start of treatment outweigh the wait in the clinic. If patients are informed of the size of the clinic and the reasons for the delay they are almost always sympathetic to the staff's problem. The alternative is ever lengthening outpatient waiting lists and an implicit selection process for treatment based on who has or has not succumbed while on the waiting list.

The editorial mentions a limit of 13 weeks between referral and first outpatient appointment, but again no qualitative weight is added to this. I doubt that a woman presenting with a breast lump or a man with a testicular swelling would conside such a wait an improvement in the quality of service.

Follow up visits should also be more structured, according to Collins. Certainly the overall number and frequency of visits could be reduced with no loss of quality, but more structuring also leads to loss of flexibility, which impairs local response to changing demands: with more structured clinics it is harder to arrange an appointment at short notice. Both routine follow up and non-routine interval visits are important in detecting recurrence of cancer, ${ }^{2}$ though they may be less important after some surgical procedures.

As with much of the present reform in the NHS, the end points indicating quality of care that are harder to measure are being sacrificed for those that are easier to measure, such as outpatient waiting times, which are often less relevant to patients' overall satisfaction, utility, and outcome.

CHARLES G KELLY

Department of Clinical Oncology,

Western General Hospital,

Edinburgh $\mathrm{EH} 42 \mathrm{XU}$

1 Collins $C$. Implementing the patient's charter in outpatien services. BM7 1992;304:1396. (30 May.)

2 Dewar JA, Kerr GR. Value of routine follow up of women treated for early carcinoma of the breast. BMF 1985;291:1464-7.

3 Coggon D, Goldacre MJ. Outpatient follow-up after appendicectomy. Lancet 1976;: 1346-7.

EDITOR, - Charles Collins's editorial on organising outpatient services to comply with the patient's charter proposes guidelines for consultation times in surgical outpatient clinics and states that efficient referral patterns may obviate the need for some outpatient attendances.

In $1990 \mathrm{I}$ reviewed all patients admitted to Sandwell District General Hospital for hernia repair during 1989 to audit assessment of patients' fitness for anaesthesia as detailed in the notes and to propose a standardised referral letter for patients with a hernia, including a questionnaire designed to identify those with potential problems regarding anaesthesia. The proposed questionnaire asked for a brief history of cardiac and respiratory disease and diabetes; current drug treatment; recent blood pressure and pulse rate; and results of analysis of urine. These details would require little extra time to provide on referral, particularly if practice records were computerised.

A total of 269 patients were reviewed. Problems of potential relevance to anaesthesia or general postoperative care were identified in 74 patients Problems were documented in the note of the initial outpatient consultation for 40 of these patients, and for only 37 of the 70 patients referred by general practitioners (four patients were interna referrals) was a problem identified in the referra letter. The questionnaire would have identified al but two of these problems (table); an outpatient visit would be unlikely to have identified the two other problems (one heart murmur, one acute chest infection). Six operations were cancelled during the year, including those for the patients with a heart murmur and acute chest infection; the four other problems would have been identified

Problems identified by proposed questionnaire

\begin{tabular}{lcc}
\hline Problem & No & $\begin{array}{c}\text { Cancelled } \\
\text { operations }\end{array}$ \\
\hline Hypertension & 33 & $2^{\star}$ \\
Cardiac disease & 13 & $3 \dagger$ \\
Chronic airway disease & 15 & $1 \neq$ \\
Asthma & 5 & \\
Diabetes & 5 & \\
Oral contraception & 1 & \\
Thyrotoxicosis & 1 & \\
Steroid treatment & 1 & \\
\hline Total & 74 & \\
\hline
\end{tabular}

Operations cancelled because of ${ }^{\star}$ uncontrolled hypertension tatrial fibrillation, congestive cardiac failure, and hear murmur; łacute exacerbation. 